Eos, Vol. 84, No. 45, 11 November 2003

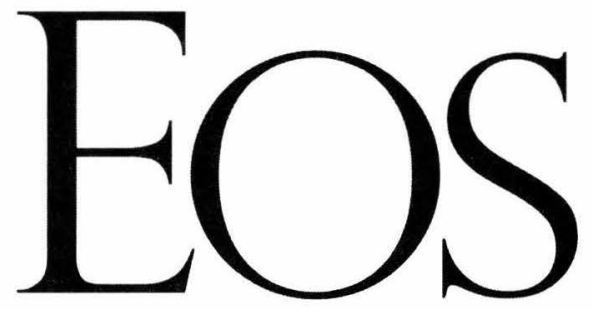

VOLUME 84 NUMBER 45

11 NOVEMBER 2003

EOS, TRANSACTIONS, AMERICAN GEOPHYSICAL UNION

PAGES 485-500

\title{
Plan for Living on a Restless Planet Sets NASA's Solid Earth Agenda
}

\section{PAGES 485, 491}

What are the most important challenges facing solid Earth science today and over the next two decades? And what is the best approach for NASA, in partnership with other agencies, to address those challenges? A new report, Living on a Restless Planet, provides a blueprint for answering these questions. The top priority for a new spacecraft mission in the area of solid Earth science over the next 5 years, according to this report, is a satellite dedicated to Interferometric Synthetic Aperture Radar (InSAR).

At the request of NASA, the Solid Earth Science Working Group (SESWG) developed a strategy for the highest priority objectives in solid Earth science for the space agency over the next 25 years. The strategy addresses six challenges that are of fundamental scientific importance, have strong implications for society, and are amenable to substantial progress through a concerted series of scientific observations from space.

Success in meeting these challenges will depend on the close coordination of and collaboration with other NASA programs, with a number of U.S. federal agencies, and with international partners. The plan recommended by SESWG is cast in terms of five observational strategies, each of which addresses multiple scientific challenges: deformation of the land surface, high-resolution topography and topographic change, variability of the Earth's magnetic field, variability of the Earth's gravity field, and imaging spectroscopy of Earth's changing surface.

Deliberations of the working group extended over 2 years (2000-2002) and included significant dialogue with the wider geophysical community. Presentations at the AGU 2000 Fall and 2001 Spring Meetings helped to build a broad consensus, and a Web site maintained reports of committee progress and invited feedback

By Sean C. Solomon, Victor R. Baker, Jeremy BlOXHAM, JEFFREY BOOTH, ANDREA DONNELLAN, Charles Elachi, Diane Evans, Eric Rignot, Douglas Burbank, Benjamin F. Chao, Alan Chave, Alan Gillespie, Thomas HerRING, Raymond JeANLOZ, JoHn LABRECQUe, BERnARd MinSTER, WALTER C. Pitman, III, Mark Simons, Donald L. Turcotte, AND MARY LOU C. ZOBACK from all interested parties. Chaired by Sean Solomon of the Carnegie Institution of Washington, SESWG included 19 representatives from universities, research institutions, NASA, and the U.S. Geological Survey. The full report can be found at http://solidearth.jpl. nasa.gov.

\section{Scientific Challenges}

The six scientific challenges identified by SESWG are:

(1) What is the nature of deformation at plate boundaries and what are the implications for earthquake hazards?

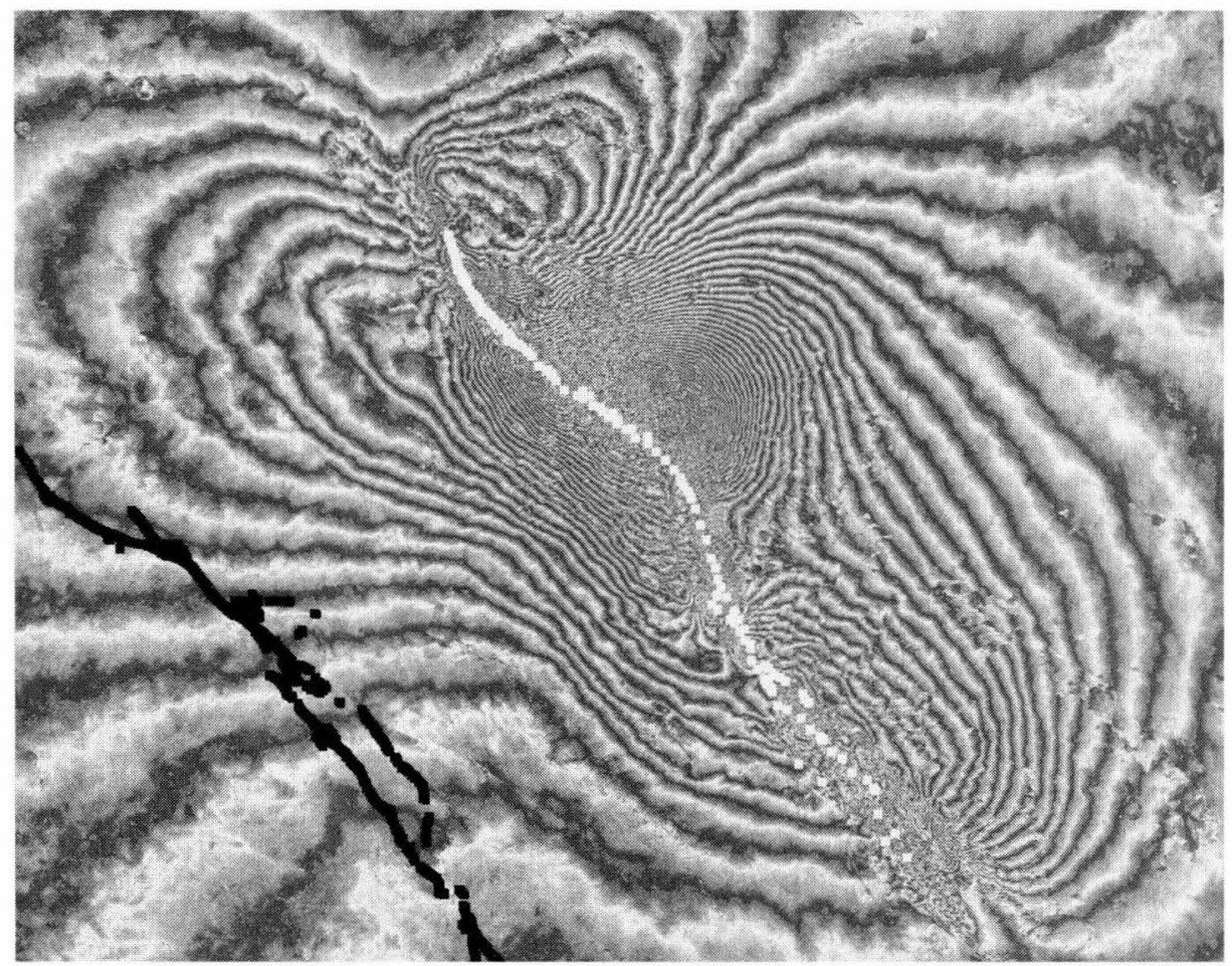

Fig. 1. Interferogram of the 1999 magnitude 7.1 Hector Mine earthquake derived from ERS-2 (European Remote Sensing satellite) SAR data. Each fringe represents $28 \mathrm{~mm}$ of line-of-sight displacement. The 45-km-long Hector Mine rupture (yellow) occurred just 7 years after the larger 1992 Landers earthquake rupture (black), providing an important constraint on models of earthquake triggering. Numerous ERS interferograms have revealed the detailed slip distribution on the fault plane, the post-seismic response of the crust to the coseismic stress change, and new evidence for triggered slip on nearby, previously mapped faults. (Data provided by the European Space Agency; figure is courtesy of D. T. Sandwell, Scripps Institution of Oceanography.) Original color image appears at back of volume.
(2) How do tectonics and climate interact to shape the Earth's surface and create natuhazards? masses, oceans, and the solid Earth and their implications for sea level change?

(4) How do magmatic systems evolve and (5) what conditions do volcanoes erupt? respond?

(6) What are the dynamics of the Earth's magnetic field and its interactions with the rth system? understanding and highlighted areas ripe for and temporal patterns of earthquakes, spacebased observations are needed for synoptic measurements of the strain field through the 
Table 1. The recommended NASA program for solid Earth science, expressed in terms of top-level goals and requirements. Defining the measurement requirements for missions that cross the traditional boundaries of these scientific challenges is best done through a unified observational strategy that combines near-term and long-term goals. Original color image appears at back of volume.

\begin{tabular}{|c|c|c|c|c|}
\hline $\begin{array}{l}\text { Observational } \\
\text { Strateges }\end{array}$ & $\begin{array}{l}\text { Immediate } \\
\text { (1-5 Years) }\end{array}$ & $\begin{array}{l}\text { Near Term } \\
\text { (5-10 Years) }\end{array}$ & $\begin{array}{l}\text { Long Term } \\
\text { (10-25 Years) }\end{array}$ & $\begin{array}{l}\text { Scientific Challenges } \\
\text { Addressed by These } \\
\text { Observations }\end{array}$ \\
\hline $\begin{array}{l}\text { Surface } \\
\text { deformation }\end{array}$ & $\begin{array}{l}\text { Single L-band, } \\
\text { dedicated } \\
\text { InSAR satellite } \\
\text { with weekly } \\
\text { global access }\end{array}$ & $\begin{array}{l}\text { Constellation of } \\
\text { InSAR satellites for } \\
\text { daily deformation } \\
\text { maps at several- } \\
\text { hundred-km width } \\
\text { and sub-mm per year } \\
\text { accuracies }\end{array}$ & $\begin{array}{l}\text { Constellation of } \\
\text { InSAR satellites in } \\
\text { low-Earth or } \\
\text { geosynchronous } \\
\text { orbits }\end{array}$ & \\
\hline $\begin{array}{l}\text { High- } \\
\text { resolution } \\
\text { topography }\end{array}$ & $\begin{array}{l}\text { Launch ICESat, } \\
\text { and demon- } \\
\text { strate imaging } \\
\text { lidar capabilities } \\
\text { in Earth orbit }\end{array}$ & $\begin{array}{l}\text { One-time global } \\
\text { mapping at } 2-\mathrm{t}(-5-5-\mathrm{m} \\
\text { resolution, } 0.5-\mathrm{m} \\
\text { vertical accuracy }\end{array}$ & $\begin{array}{l}\text { Continuously } \\
\text { operating, target- } \\
\text { ed mapping cap- } \\
\text { ability with } 1-\mathrm{m} \\
\text { resolution, } 0.1-\mathrm{m} \\
\text { vertical accuracy }\end{array}$ & \\
\hline $\begin{array}{l}\text { Variability } \\
\text { of Earth's } \\
\text { magnetic field }\end{array}$ & $\begin{array}{l}\text { Analyze } \\
\text { current } \\
\text { geomagnetic } \\
\text { satellite data }\end{array}$ & $\begin{array}{l}\text { Constellation of } \\
4-6 \text { satellites in } \\
800-k m \text { polar } \\
\text { orbits }\end{array}$ & $\begin{array}{l}\text { 12-satellite } \\
\text { constellation in } \\
300-\text { and } 800-\mathrm{km} \\
\text { orbits }\end{array}$ & \\
\hline $\begin{array}{l}\text { Variability } \\
\text { of Earth's } \\
\text { gravity field }\end{array}$ & $\begin{array}{l}\text { Analyze } \\
\text { current Gravity } \\
\text { Recovery and } \\
\text { Climate } \\
\text { Experiment } \\
\text { data }\end{array}$ & $\begin{array}{l}\text { Demonstration } \\
\text { of satellite-to- } \\
\text { satellite laser } \\
\text { interferometry } \\
\text { technology }\end{array}$ & $\begin{array}{l}\text { Gravity } \\
\text { measurements } \\
\text { from space } \\
\text { improved by } \\
2-3 \text { orders of } \\
\text { magnitude }\end{array}$ & \\
\hline $\begin{array}{l}\text { Imaging } \\
\text { spectroscopy } \\
\text { of Earth's } \\
\text { changing } \\
\text { surface }\end{array}$ & $\begin{array}{l}\text { Continued air- } \\
\text { and spaceborne } \\
\text { imaging in the } \\
\text { solar reflected } \\
\text { spectrum }\end{array}$ & $\begin{array}{l}\text { Satellite with } 100-\mathrm{km} \\
\text { swath and } 30-\mathrm{m} \\
\text { spatial resolution in } \\
\text { the visible/near- } \\
\text { infrared }\end{array}$ & $\begin{array}{l}\text { Continuous } \\
\text { full-spectrum } \\
\text { spaceborne } \\
\text { global imaging } \\
\text { with frequent } \\
\text { revisits }\end{array}$ & 20 \\
\hline \multicolumn{5}{|l|}{ Legend: } \\
\hline \multicolumn{3}{|c|}{$\begin{array}{l}\text { What is the nature of deformation at plate } \\
\text { boundaries and what are the implications } \\
\text { for earthquake hazards? } \\
\text { How do tectonics and climate interact to } \\
\text { shape the Earth's surface and create } \\
\text { natural hazards? }\end{array}$} & $\begin{array}{l}\text { Exy } \\
\text { How do } \mathrm{m} \\
\text { evolve anc } \\
\text { conditions }\end{array}$ & $\begin{array}{l}\text { gmatic systems } \\
\text { under what } \\
\text { lo volcanoes erupt? } \\
\text { e dynamics of the mantle } \\
\text { ad how does the Earth's } \\
\text { ond? } \\
\text { he dynamics of the } \\
\text { ggnetic field and its }\end{array}$ \\
\hline
\end{tabular}

entire earthquake cycle, including episodes of aseismic accumulation of strain. Such measurements can provide insights into how stress is transferred between faults, the fraction of strain that is accommodated seismically, and ultimately how faults fail. Diverse temporal and spatial scales for the governing processes dictate a variety of specific observational approaches. Satellites devoted to InSAR measurements together with Global Positional System (GPS) networks are needed to provide dense, frequent sampling and high-accuracy observations of changes at the Earth's surface (Figure 1). Existing and planned seismic networks and borehole sensors will complement space-based, low-frequency sounders, and highly accurate gravity measurements can help to characterize subsurface regions subject to seismic hazards.

One or more satellites dedicated to InSAR measurements will provide an essential component of the EarthScope Program, other flood waves will migrate through a catchment and how much sediment will be eroded, transported, and deposited during a storm.

Remotely sensed data play an integral role in reconstructing the recent history of the land surface and in predicting hazards due to events such as floods and landslides. Information needed to address this challenge includes surface, subsurface, and hydrologic characteristics. These categories have a range of observational requirements. Quantities that change rapidly, such as river stage or precipitation, call for hourly measurements, whereas others might require only seasonal measurements (e.g., vegetation) or occasional (5-10 yr) quantification (e.g., soil composition and thickness).

Inasmuch as paleo-environmental and historical data have clearly documented sea level changes in the past, new scientific information on the nature and causes of sea level changeand the development of a quantitative predic tive capability - are of utmost importance for the future. This topic is inherently an interdisciplinary scientific problem impacted by the fluid, cryospheric, and solid Earth, and addressed within NASA by the Cryospheric Science, Ocean Science, Hydrology, and Solid Earth Science Programs.

The $10-20-\mathrm{cm}$ global rise in sea level recorded over the last century has been broadly attributed to two effects: the steric effect (thermal expansion and salinity-density compensation of sea water) of changes in global climate and mass-budget changes due to a number of competing geophysical and hydrological processes in the solid Earth-atmospherehydrosphere-cryosphere system. The NASA Solid Earth Science Program can make a fundamental contribution to this problem by separating the two effects through the combined use of space geodetic measurements of sea surface and glacier topography and time-variable gravity.

The eruptive power and often-long intervals of quiet dormancy render volcanoes both difficult objects of study and dangerous geographic neighbors to population centers. The threat of eruption is always there, but because eruptions are episodic, the fastest route to general understanding is to take advantage of observations of volcanic activity on a global scale. Including remote terrestrial and undersea volcanoes, there are thousands of volcanic centers whose level of activity is poorly known.

Indicators of activity include surface deformation, seismicity, changes in gravity, fluxes of gasses, and actual eruptions. Little is known, however, of how these phenomena are interrelated. The physical mechanisms that cause surface deformation and those that control the rates and styles of eruptions are similarly poorly understood. The ability to predict the timing, magnitude, and style of volcanic eruptions is a laudable but still generally unmet goal.

Mantle convection is the engine responsible for plate motions, seismicity, volcanism, and mountain building. The deformation of the Earth's surface required to accommodate plate tectonics occurs primarily along plate 


\section{Eos, Vol. 84, No. 45, 11 November 2003}

boundary faults and relatively broad zones of deformation adjacent to the plate boundaries in the continents. The forces that drive the motions of the plates, however, are not well quantified.The global gravity field and longwavelength topography provide key integrative measures of density anomalies associated with mantle convection, although their interpretation requires information on the structure of the tectonic plates and the variation of viscosity within the mantle.

Improved information on plate characteristics and mantle viscosity can come, in turn, from measurements of the time-dependent response of global gravity, topography, and Earth rotation to loading and unloading by glaciers, oceans, and other forcings.

The problem of explaining the origin of the Earth's magnetic field was once ranked by Albert Einstein as among the three most important unsolved problems in physics. Although today it is widely recognized that a dynamo operating in the fluid outer core generates the Earth's magnetic field, the details of how that dynamo works remain far from understood. Over the past 150 years, the main (axial dipole) component of the Earth's magnetic field has decayed by nearly $10 \%$, a rate ten times faster than if the dynamo were simply switched off.To that extent, the dynamo today is operating more as an anti-dynamo, a destroyer of the dipole part of the field. Intriguingly, this decay rate is characteristic of magnetic reversals, which paleomagnetic observations have shown occur on average, though with great variability, about once every half million years.

Geographically, the recent dipole decay is due largely to changes in the field in the vicinity of the South Atlantic Ocean. This pattern is connected to the growth of the South Atlantic Magnetic Anomaly, an area in which the field at the Earth's surface is now about $35 \%$ weaker than would be expected. This hole in the field has serious implications for low-Earth-orbit satellite operations since it impacts the radiation dosage at these altitudes. How much longer will the South Atlantic Magnetic Anomaly continue to grow? How large will it become? Is the field reversing? Long-term satellite observations combined with numerical dynamo modeling will advance our understanding and allow for modeling of the evolution of this anomaly.

\section{The Integrated Program}

To make substantial progress toward answering each of the six challenges for solid Earth science, NASA must formulate a broadly conceived program with both near-term goals and clear steps toward longerterm objectives (Table 1).
The interconnected nature of solid Earth science means that the most challenging issues in the field today bridge several disciplines. As such, defining the measurement requirements to address these challenges is best done through a unified observational strategy. Such a broad strategy incorporates diverse methodologies (including space-borne and ground measurements), technological advances, and complementarity among observations. SESWG has recommended the following observational strategies to address the fundamental challenges to solid Earth science:

(1) Surface deformation

(2) High-resolution topography

(3) Variability of Earth's magnetic field

(4) Variability of Earth's gravity field

(5) Imaging spectroscopy of Earth's changing surface

Continued development of space geodetic networks and the International Terrestrial Reference Frame, as well as investment in promising techniques and observations, such as subsurface imaging using low-frequency sounders, are important components of an overall program.

A dedicated research and analysis program is a critically important core activity, to ensure that newly acquired data are fully analyzed, to provide the new ideas for instrument and mission development, and to foster unexpected scientific discoveries. SESWG recommendations include significant investments in computation and modeling for testing theories and predictions. A number of observations needed over the next two and a half decades require a continuing investment in advanced technology development. This modular yet broadly interlinked program architecture offers flexibility to change as scientific discoveries and programmatic requirements dictate.

NASA's role in observations is primarily the development of satellite missions, but such projects cannot be as effective as possible without complementary terrestrial observations and the requisite partnerships with other programs and agencies. The SESWG strategy builds on current capabilities and resources. It requires data from missions and instruments that have recently flown, that are currently flying, and that are planned for the very near future (e.g., Advanced Spaceborne Thermal Emission and Reflection Radiometer or ASTER, Shuttle Radar Topography Mission or SRTM, Satelite de Aplicaciones Científicas - C or SAC-C, Challenging Mini-satellite Payload or CHAMP,and Gravity Recovery and Climate Experiment or GRACE). It also relies on data from missions that are currently supported by other scientific disciplines, such as the Global Precipitation Mission and the River Discharge and Cold
Regions Exploratory Missions. The SESWG strategy leverages collaborations and partnerships to the largest extent possible with other government agencies, the private sector, and the international community. The focus in the report is largely on new observational requirements that promise the greatest advance toward addressing the key challenges and on the implications of those requirements for investments in new technology.

For the next 5 years, the new space mission of highest priority for solid Earth science is a satellite dedicated to InSAR measurements of the land surface at L-band. Such a mission would address the most urgent objectives in the areas of plate-boundary deformation, landsurface evolution, ice and sea level change, volcanism, and mantle dynamics. Over the next 5 to 10 years, the scientific challenges facing solid Earth science can be met by NASA leading or partnering in space missions involving constellations of satellites dedicated to InSAR and magnetic field measurements, new instruments for mapping global topography and its temporal changes and for imaging spectroscopy across a broad portion of the electromagnetic spectrum, and a GRACE follow-on to improve the resolution of temporal changes in Earth's gravity field. In the 10-25year time frame, several techniques offer the promise to contribute in a major fashion to solid Earth science but require substantial technology development. A fully realized program should contain elements that encompass not only new observations but also sustained investment in research and analysis, information systems, new technologies, supporting infrastructure, and education and public outreach.

\section{Author Information}

Sean C.Solomon, Carnegie Institution of Washington; Victor R. Baker, University of Arizona, Tucson; Jeremy Bloxham, Harvard University, Cambridge, Mass.; Jeffrey Booth, Andrea Donnellan, Charles Elachi, Diane Evans, and Eric Rignot, Jet Propulsion Laboratory, California Institute of Technology, Pasadena; Douglas Burbank, University of California, Santa Barbara; Benjamin F.Chao, NASA Goddard Space Flight Center, Greenbelt, Md.; Alan Chave, Woods Hole Oceanographic Institution, Mass.; Alan Gillespie, University of Washington, Seattle; Thomas Herring, Massachusetts Institute of Technology, Cambridge; Raymond Jeanloz, University of California, Berkeley; John LaBrecque, NASA Headquarters; Bernard Minster, University of California, San Diego; Walter C. Pitman, III, Lamont Doherty Earth Observatory, Columbia University, N.Y.; Mark Simons, California Institute of Technology, Pasadena; Donald L.Turcotte, University of California, Davis; and Mary Lou C. Zoback, U.S. Geological Survey, Menlo Park, Calif. 